\title{
MONITORING OF CUTTING CONDITIONS WITH THE EMPIRICAL MODE DECOMPOSITION
}

\author{
Piotr Wolszczak', Krystian kygas' ${ }^{1}$, Grzegorz Litak ${ }^{1}$ \\ 1 Lublin University of Technology, Mechanical Engineering Faculty, Department of Automation, Nadbystrzycka \\ 36, 20-618 Lublin, Poland, e-mail: p.wolszczak@pollub.pl, k.lygas@pollub.pl, g.litak@pollub.pl
}

Received: 2016.12.15

Accepted: 2017.02.01

Published: 2017.03.01

\begin{abstract}
In this paper, we apply empirical mode decomposition by Huang and Hilbert to transform signals recorded during a milling process. Vibroacoustic sensors recorded vibrations of a tool-workpiece system while milling with the end mill of a special shape of "Hi-Feed". The results of Huang-Hilbert analysis provide the information about amplitudes and frequencies of empirical modal components. Application of HuangHilbert transform to cutting conditions monitoring allows the separation of various vibration components caused by phenomena associated with the drive system and the machine components. Therefore, the analysis highlights vibrations caused by known sources of vibration, such as spindle speed, the number of teeth of the cutting tool or the frequency of vibration tools. Furthermore, signal components generated in the cutting zone were identified. The resulting information helps to assess the working conditions of cutting tools, selection of cutting parameters and tool wear monitoring.
\end{abstract}

Keywords: monitoring, cutting condition, milling process.

\section{INTRODUCTION}

The recent development of materials and new technologies used in the construction of machines demands to improve the tools used for the machining [1]. Improving the tools consists of applying wear resistant coatings, adjusting the geometry of cutting tools and machining parameters and the identification of the dynamical system response [5, $7,11-12,14-15]$. This trend can be seen in aerospace and automotive industries, where the use of ultra-light and durable materials is implemented. In many industries, it is also important to reduce manufacturing costs and manufacturing time, including time to implement the production of a new type of material, e.g. composite material, Inconel and stainless steel $[7-10,16]$.

To assess the working conditions of cutting tools, in the present paper, we use the method of empirical mode decomposition (EMD) by the algorithm developed by Huang and Hilbert transform [2-4, 6-7]. As a result, such a decomposition together with Hilbert spectral analysis provide the amplitude and frequency of the signal components forming the signal being analyzed in the time domain. Consequently, the particular empirical modes characterize phenomena accompanying an aggressive type of machining, during which induced chatter vibration in a complex system of cutting-machine-tool-workpiece. Separation of the signal components, based on their frequency and amplitude information can be confirmed by the tool vibrations during toolworkpiece material interactions and a loss of contact. This information allows the selection of cutting parameters, their optimization and, finally, monitoring the working tools conditions, including cooling, lubrication and wear of tools. 


\section{EXPERIMENTAL SET UP AND WORKPIECE MATERIAL}

Examples of the cutting signals have been collected during the extensive research and development conducted in cooperation with the manufacturer of special cutting tools. Research focused on adaptation the geometry of tools and parameters of their work to the kind of workpiece and requirements for tool life as well as productivity of the manufacturing process for which they are intended.

Measured objects were end mills in the shape of a "Hi-Feed" with diameters of $4.8 \mathrm{~mm}$, while the material was machined the alloy of Inconel 713 belonging to the class of super-alloys difficult to machine. During the milling process, spindle vibrations were developed as a response to forces acting on the blade cutter when cutting. Figure 1 shows samples of the vibration signal of a cutting tool during milling, recorded using a measurement system equipped with sensors Sensor NVH Hansford HS-102 with a measuring range $16 \mathrm{KHz}$ and sensitivity of $100 \mathrm{mV} / \mathrm{g}$. The sensors provide acceleration signal that is then filtered by a Butterworth high pass filter to eliminate a possible signal drift and to obtain the average value equal to zero. The sensors were mounted on a milling spindle to the magnet in a plane perpendicular to the axis of the milling cutter in the $\mathrm{X}, \mathrm{Y}$ and angle 45 st. the $\mathrm{X}$ and $\mathrm{Y}$ axis. The signals were recorded by data acquisition cards from National Instruments NI USB6341 type, equipped with 16bit processing speed $500 \mathrm{kS} / \mathrm{s}$. The recorded acceleration signal was also subjected to successive operations of numerical integration to achieve the waveform velocity and displacement sensors. These traces provide some additional information about the forces acting on the spindle. Note that due to the ambiguity of the interpretation of the signal obtained from a displacement sensor noise and vibration analysis, with their applications, have a comparative nature. End mills of different diameters, types of cover, geometry and number of teeth were compared in pairs. The present dynamical tests were conducted at the request of a manufacturer of special tools (tailored to the needs of the production process of the company ordering tool) to assess the benefits of changes in redesigned tools.

In the present study, the waveforms, recorded during operation of cutters with a diameter of $4.8 \mathrm{~mm}$, were designed to make grooving with a width equal to the cutter diameter and a depth of more than 7 times larger than the diameter of the cutter. The type of material determined the selected shape of the cutter-type "Hi-Feed" and the shape of the groove performed. In our case, the operating (rotation) direction was perpendicular to the resulting cutting direction effecting, on
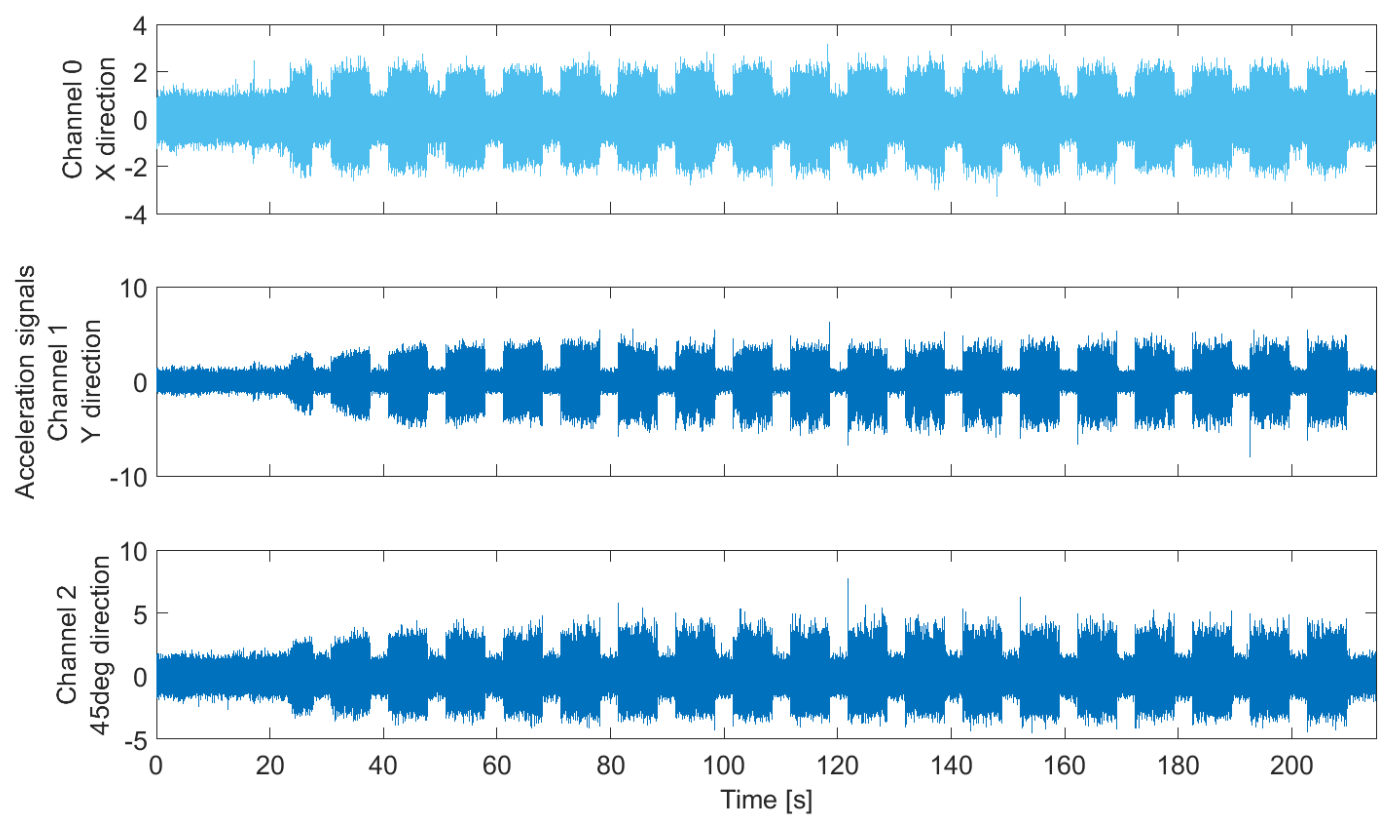

Fig. 1. Acceleration signals (vibration sensors mounted on the spindle in the X, Y directions and 45 deg., corresponding to the sensor orientations, respectively) recorded during the work tool cutter pass in y direction. The end mill was of a diameter of $4.8 \mathrm{~mm}$ in the shape of a "Hi-Feed" during the performing of the groove 
a)

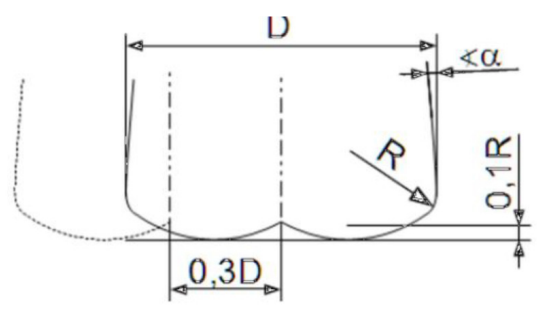

b)

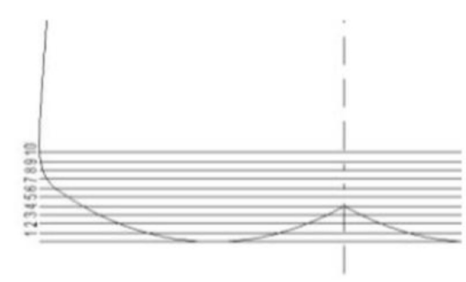

Fig. 2. End mill shape - "Hi-Feed": a) the geometrical characteristic, b) the cutting depth during successive cutting [6]

the way, the easy removal of chips from a narrow groove. These kind of tools enable a low roughness of with higher feed and they are often used in finishing operations.

In Figure 2a we show the characteristic dimensions and geometric shape of "Hi-Feed". The cutting depth was 0.1 of the radius, $R$. The side profile tool is tilted by the angle, , to the line forming a cylinder with a diameter, $D$. Figure $2 \mathrm{~b}$ shows schematic cutting depths during subsequent passes of the tool in the workpiece material.

In the analysis by Hilbert-Huang one performs the so-called signal decomposition into empirical modes (Huang decomposition-EMD). Therefore the acceleration $A_{v}(t)$ is composed of modal components $A_{\mathrm{y}}{ }^{1}(t), A_{\mathrm{y}}{ }^{2}(t), \ldots, A_{\mathrm{y}}{ }^{\mathrm{m}}(t)[4]$ :

$$
A_{y}(t)=\sum_{j=1}^{m} A_{y}^{j}(t)+r_{m}
$$

where $r_{\mathrm{m}}$ is a truncation error. Each next empirical $j$ mode is defined after subtracting average of maximum and minimum values interpolated by cubic splines of the local envelope $A_{x}^{j-1}(t)$. Note that the first mode $A_{y}^{1}(t)$ is obtained from the original signal $A_{\mathrm{y}}(t)=A_{\mathrm{y}}^{y_{0}}(t)$ and the Huang decomposition procedure. The first 6 modes obtained using the above schema from Figure 1 (channel 1) are plotted in Figure 3a.

\section{RESULTS OF SIGNAL ANALYSIS}

Huang decomposition algorithm (EMD) allows us to determine modal signal components of different frequency (sorted from fast to slow components) and its corresponding amplitude. In Figure 3 we illustrate an exemplary waveform recorded during the operation of the end mill shaped as a cutter-type of „Hi-Feed". Recording time interval was two seconds, while the sampling rate was fixed at $4 \mathrm{kHz}$. Figure 3a) shows the recorded signal (raw), and another fashion obtained by decomposition algorithm Huang. On the other hand Figure $3 b$ ) illustrates the spectrum obtained with the Fast Fourier Transform (FFT).

Figure $3 \mathrm{~b}$ shows clear frequency bands characterized by different Huang modes (signal components of vibration tools). This measurement was performed at a speed of $7500 \mathrm{rpm}(125 \mathrm{~Hz})$, which is visible in the spectrum module 5 . The cutter had 4 blades, so the frequency of going into the next blade in the material amounted to about $500 \mathrm{~Hz}$, which is included in the spectrum of mode No. 3 . The higher number of spectra are recorded for higher frequencies as illustrated in modes 1 and 2. These frequencies are appearing in the system response as the result of the cutting phenomena occurring in the cutting zone, including the process of separation of the material by the cutter blades, vibrations of rods (having a small diameter), and also changes in the cutting depth for different phases of a blade passing through the material during rotation. Due to the method of calculating the FFT signal components caused by one type of phenomenon can lead to the formation of the spectrum peaks in different places. However, these examples demonstrate the utility of the Huang decomposition in monitoring the cutting conditions.

Figure 4 shows a comparison of the decomposition of the signal recorded during cutting move (Fig. 4a)), and during rapid linear move (Fig. 4b)) when the spindle enabled turnovers and moved without contact of the tool with the workpiece. Clear identification of signal components spectra (vibration) corresponding to work-related powertrain of cutting machines allows them to be distinguished from the signal recorded during cutting operation of the tool and analyze only those components that have been caused by a phenomenon resulting from machining.

Analysis of phenomena occurring in the cutting zone also includes a simulation of finite element (FE) analysis of tool vibrations (deformation) $[13,17]$. Figure 5 shows an example of numerical simulation of machining using the cutter of a "Hi-Feed" shape. It is interesting to compare the local temperature accompanying the machin- 

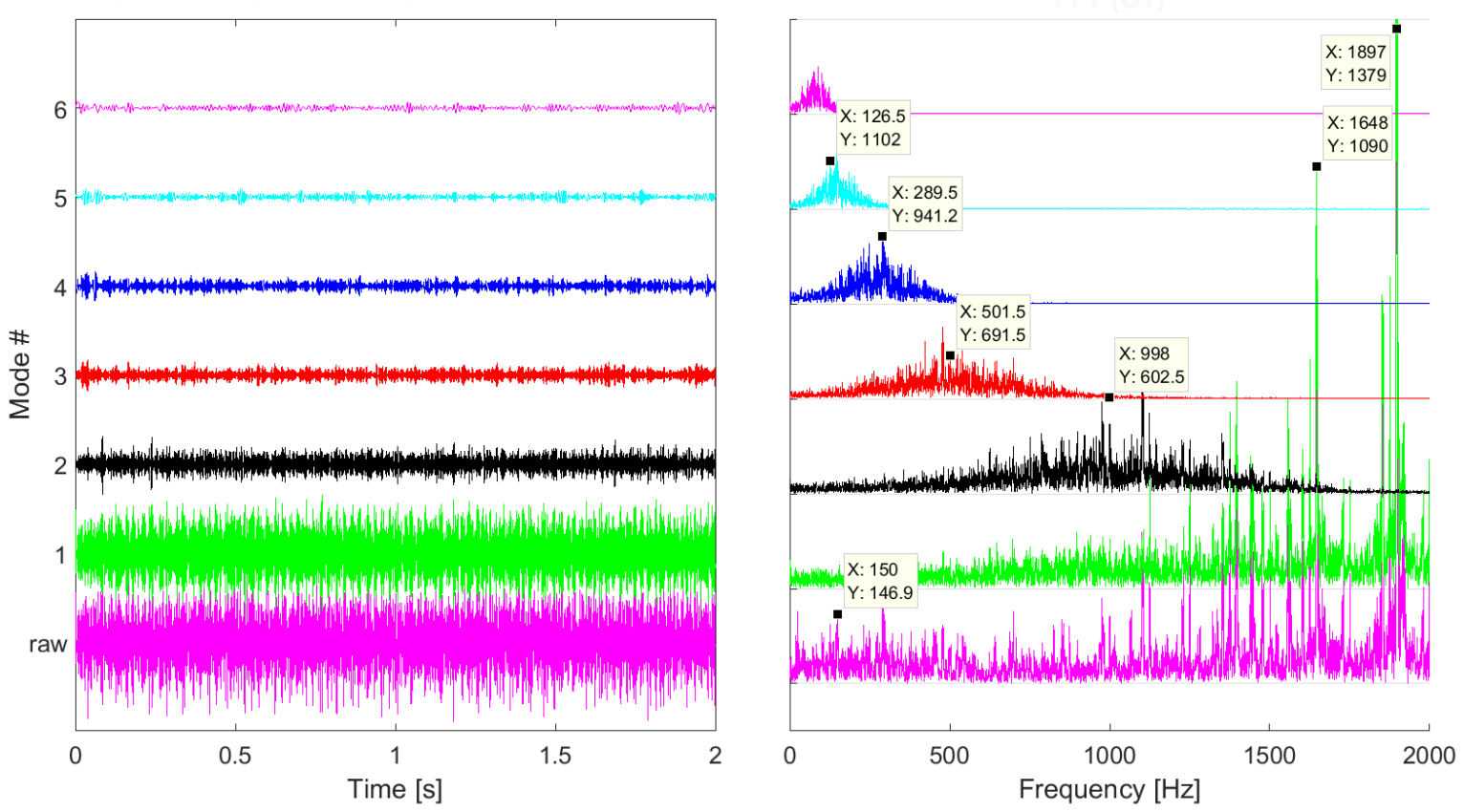

Fig. 3. Original signal (raw) and EMD (1-6) of the working interval (passage \# 5 from Fig. 1 channel 1) of the end mill cutter of the shape of a "Hi-Feed" (a) and the corresponding FFT spectra (b)
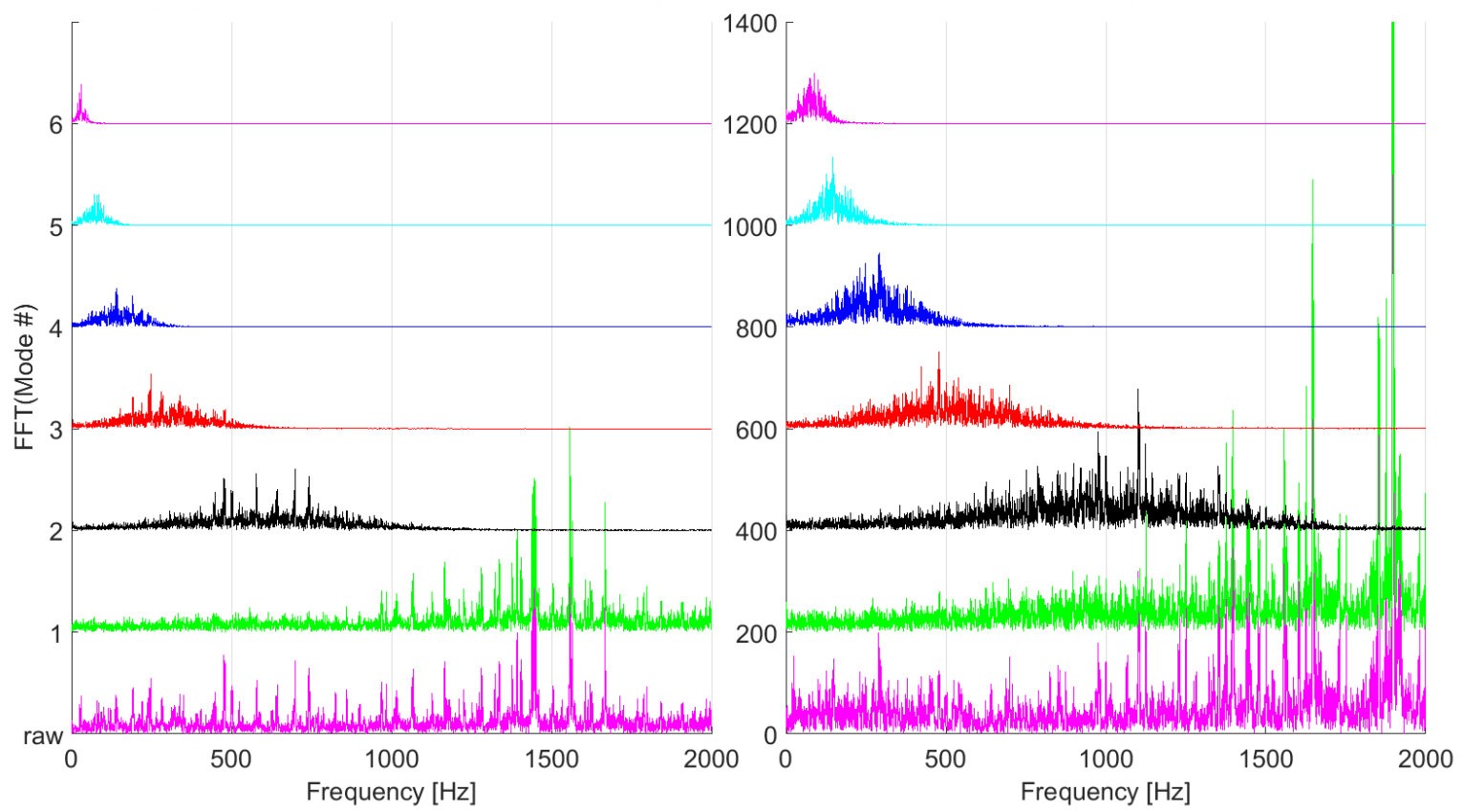

Fig. 4. Fourier spectra of Huang modes determined with a waveform during tool linear movements (a) and cutting operation (b)

ing process with tools of two and four blades. The simulation included the transition of a single blade through workpiece material during feed movement. The transition time was $8 \mathrm{~ms}$. By using FE simulations we try to determine the probable causes of tool vibration with a frequency of ap- proximate $1000 \mathrm{~Hz}$. This signal frequency is contained in the plot No. 2 in Figure 4b. Note that the spectrum of mode No. 2 is characterized by a wide frequency distribution. Based on three-dimensional models the machining process forces acting on the tool can be derived. 
a)

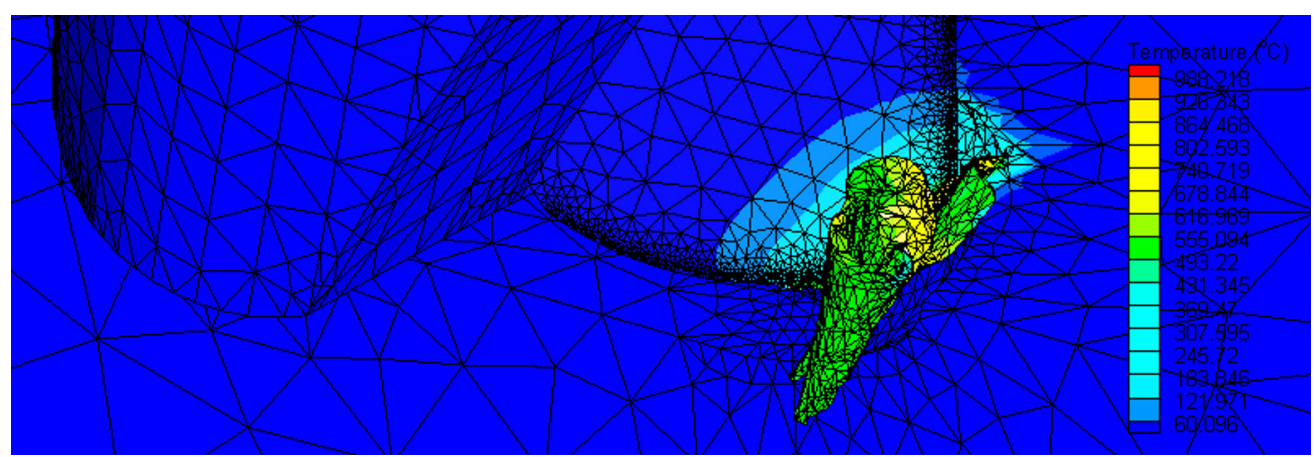

b)

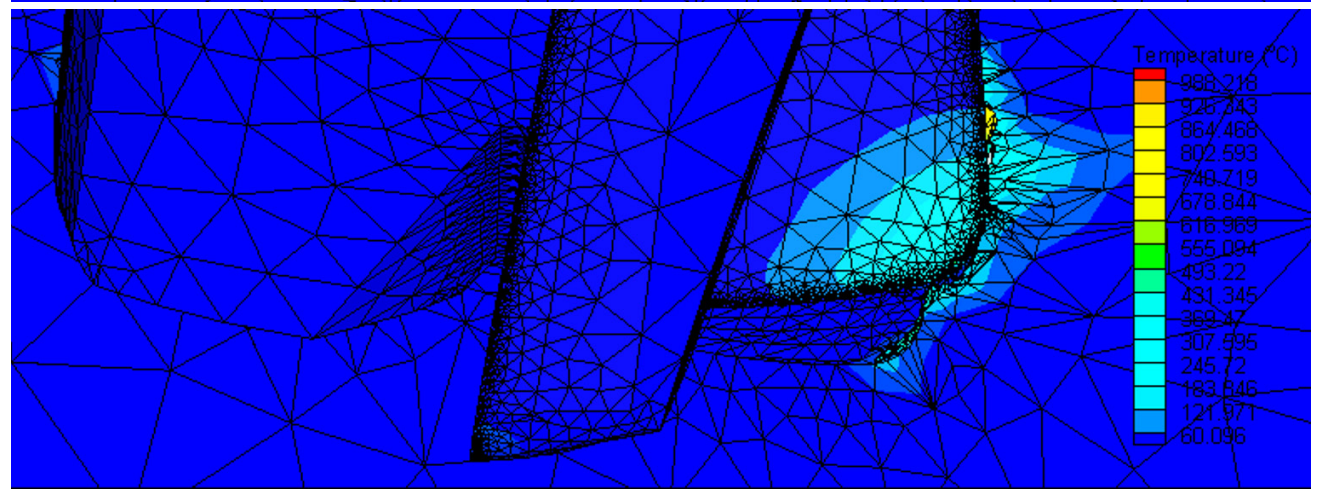

Fig. 5. Numerical simulation of metal milling using a cutter-type "Hi-Feed" a) two blade cutter, b) four blade cutter. Color of shading nets correspond to temperatures $\left[{ }^{\circ} \mathrm{C}\right]$ of the workpiece material and tools

The corresponding results of numerical simulation shown in Figure 6 in the form of waveform forces acting on the tool in $\mathrm{X}$ and $\mathrm{Y}$ are characterized by repeating periods of variability. Periodicity of the waveform generated during the simulation is in the time range of $0.75-1.05$ $\mathrm{ms}$, which indicate a frequency of $952-1333 \mathrm{~Hz}$.
It covers the middle part of the spectra mode No. 2. It should be noted that the spectrum obtained from recording of 2 seconds long, while the numerical simulation included $3.3 \mathrm{~ms}$.

EMD by Huang involves the release of component signals based on their frequencies and amplitudes. Taking into account the value of the

a)

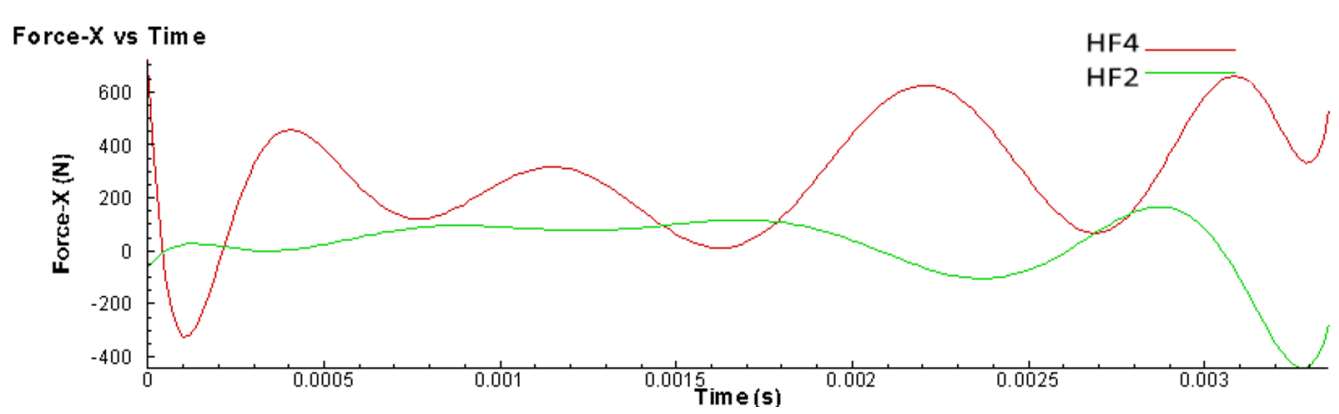

b)

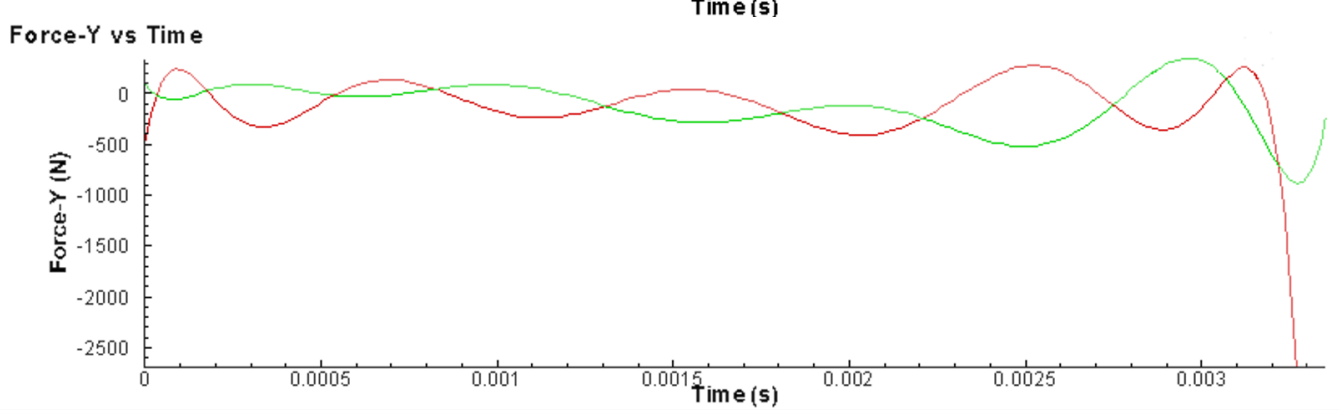

Fig. 6. The mean values of the forces acting on the blades of tools (tool) against time. The results obtained during numerical simulation in directions a) $\mathrm{X}$ and b) $\mathrm{Y}$ 

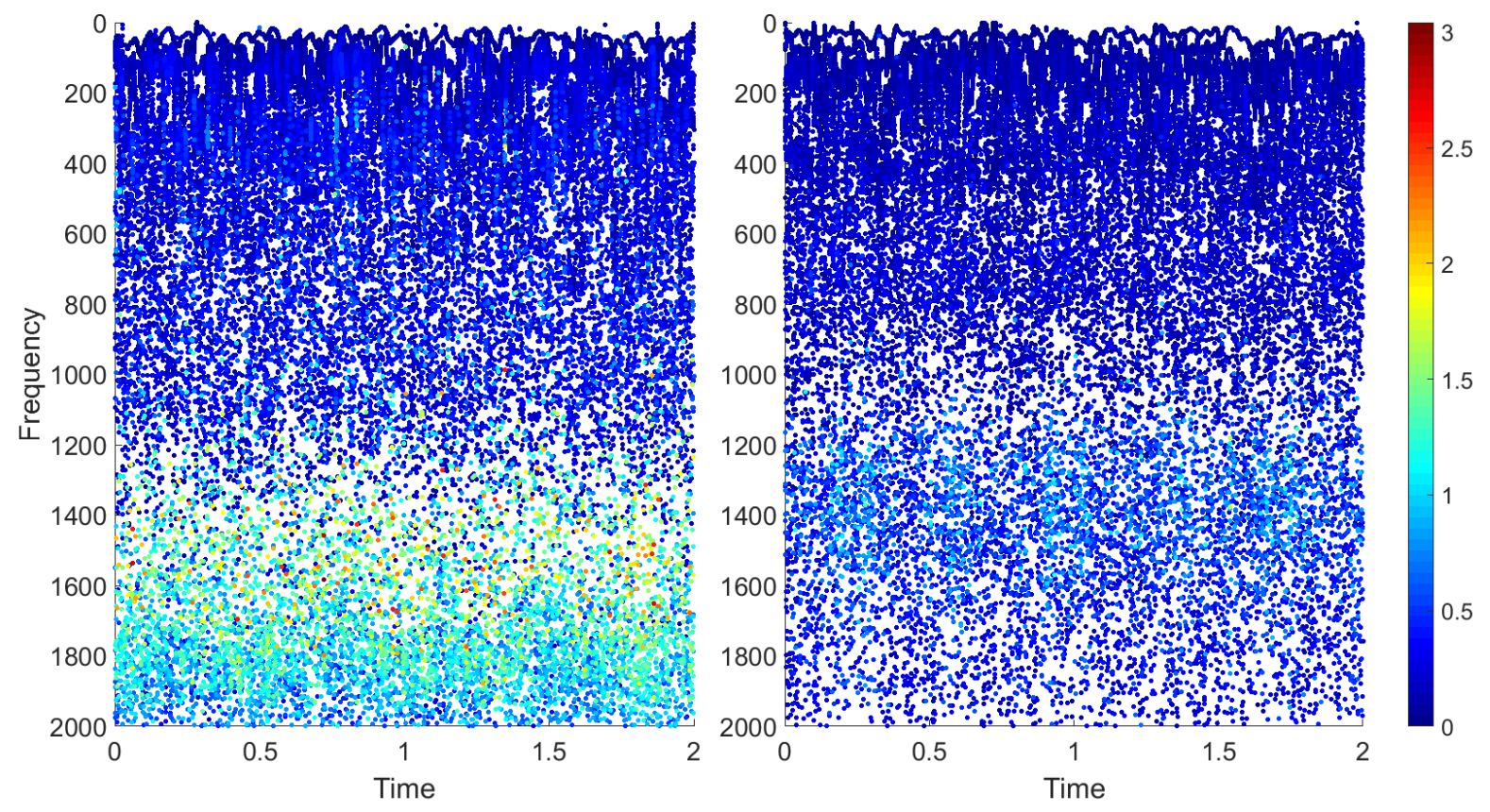

Fig. 7. Hilbert-Huang cutting results for a selected time interval with "Hi-Feed" end mill during tool linear movements (a) and cutting operation (b). Amplitudes and frequencies of the first 6 modes are included

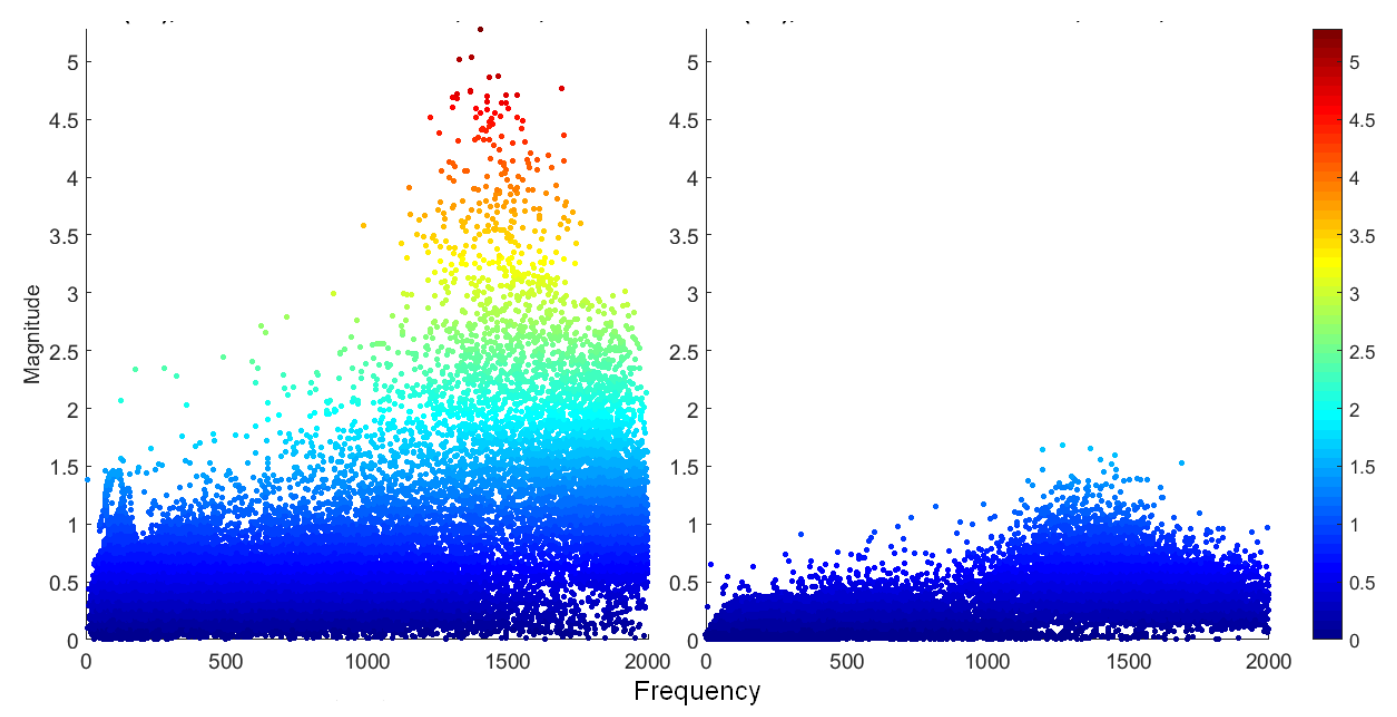

Fig. 8. Hilbert-Huang cutting results for a selected time interval with "Hi-Feed" end mill during tool linear movements (a) and cutting operation (b). Amplitudes and frequencies of the first 6 modes are included. The colours correspond to Figure 7.

amplitude signals characterizing components to specify the sources of signals and their detailed analysis of their causes. However, in the case of Fast Fourier Transform, the signal component selection is based on the frequency. An additional difficulty in interpreting the cause fragments of component signals, which have been identified as having multiple original frequencies and the spectral form a separate cluster (especially for nonsta- tionary intervals). The FFT is based on a quantitative assessment in the frequency domain, while the decomposition of the Hilbert-Huang allows simultaneous imaging the amplitude and frequency spectrum in the time domain. This feature is particularly useful in the evaluation of cutting conditions in real time in an industrial environment.

Figure 7 shows a chosen 2 -second interval of the tool passes (write spindle vibration) in one 
operation during the catting work movement (a) and rapid linear motion (b), which were subjected to EMD and Hilbert spectral analysis. Shown by points the instantaneous frequency (vertical axis) and amplitude (color point) six primary modes Hilbert-Huang. Accounts for the overlap results in the graph are not visible to spot the size of the plane frequency (time), so their numbers in specific areas can be estimated on the basis of the number of close neighbors.

The passages shown in Figure 7 are significantly different due to the amplitude of Huang modes at higher frequencies over $1200 \mathrm{~Hz}$. It is also worth noting that the amplitudes of the working passage can increase (Fig. 7a) with respect to vibration coming from the machine in the range of approximately $100-500 \mathrm{~Hz}$. This analysis allows us to distinguish the vibrations caused by the driving elements of the machine from vibrations generated by the cutting tool.

Figure 8 shows a magnitude (versus frequency) of instantaneous decomposition of the HilbertHuang while cutter working and rapid tool movement. This projection allows us to specify the differences between the waveforms. Vibration areas shown in Figure $8 \mathrm{~b}$ characterize the machine to operate rapid tool movement over the work material in the same direction, while cutting operation is shown in Figure 8a. The area on Figure 8b) reaches a level 0.5 on the amplitude axis, at the frequency range of $0-1000 \mathrm{~Hz}$, and in the adjacent area reaches a value of about 1 on the amplitude axis at the frequency range of 1000-2000 Hz. Similar clusters of points are shown in the Figure $8 \mathrm{a}$, The amplitude values are reinforced by almost twice the force of operation of the cutting tool. The other points shown in Figure 8a) are caused by material separation from the workpiece by the tool tip.

Preliminary assessment of the quality of cut is therefore the observation of points over the boundary of about 2-axis acceleration amplitudes recorded by sensors and undergoing decomposition Hilbert-Huang. High amplitudes characterize the forces acting on the cutting tool. During selecting parameters of machining it is advisable to reduce vibration amplitudes.

The individual Huang modes of Figure 3 can be analysed using the frequency amplitude plots. Consequently, in Figure 9 we show the examples Hilbert transform results for particular modes. Here, by different colours we denoted two cases: red colour - cutting operation, and blue colour - tool linear movement. Note that the combined results for these two cases and all the modes together are the plotted in Figure 7.

Figure 10 shows an example of application of the Hilbert-Huang decomposition to monitor the initial wear of the cutting tool. Decomposition results are shown in wave forms for observing the respective amplitudes of vibrations of different frequency components. In the initial portion of the waveform is visible phase of insertion tool during
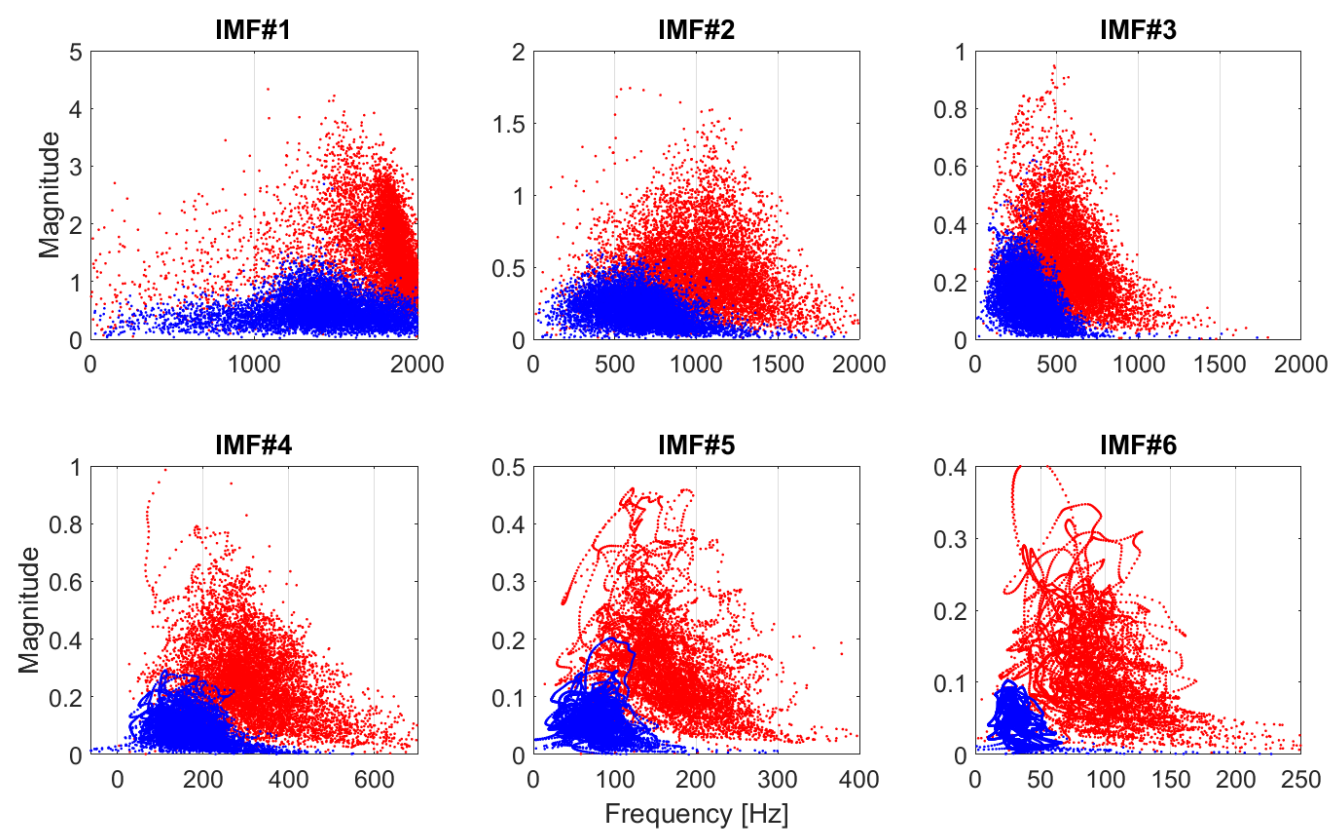

Fig. 9. Dependences amplitude and frequency modes of decomposition empirical Hilbert-Huang sample runs of the tool type "Hi-Feed" in the course of: red - cutting operation, and blue - tool linear movement 
the subsequent passes in accordance with Figure 2. In the following, visible downward trend of amplitude values associated with the completion of the initial phase of the running blades of the tool.

\section{CONCLUSIONS}

During monitoring of the cutting conditions, by using vibration sensors, the recorded signals are disrupted by components generated by the drive system and the mechanisms of the cutting machine. The application of Huang EMC and Hilbert transform can extract signal components of vibration with respect to their amplitude and frequency and identify those related directly to the milling process. An additional Fourier spectral analysis (FFT) applied to the Huang modes were used to determine the frequency characterizing the known sources of vibration, such as spindle speed, the number of teeth of the cutting tool and the frequency of vibration instruments designated at the numerical simulations. The graph amplitude (frequency) modes Hilbert-Huang separated signal components generated in the cutting zone.

The decomposition of the Hilbert-Huang allows simultaneous imaging of the amplitude and frequency spectrum in the time domain. This feature is particularly useful in the evaluation of cutting conditions in real time in an industrial environment.

Separation of the signal component, account for their frequency and amplitude information was also confirmed on the tool vibrates during insertion of the material of the panels. This information allows the selection of cutting parameters, and their optimize and monitor the conditions of work tools, including cooling, lubrication and wear of tools. The waveforms demonstrate the usefulness of Huang decomposition and transformation of Hilbert in the monitoring of cutting conditions.

\section{REFERENCES}

1. Altintas Y. Manufacturing automation. Metal cutting mechanics, machine tool vibrationa, and $\mathrm{CNC}$ design. Cambridge, New York 2000.

2. Feldman M. Hilbert transform in vibration analysis, Mechanical Systems and Signal Processing 25 (2011) 735-802.

3. Hilbert D. Grundzuege einer allgemeinen Theorie der linearen Integralgleichungen, Chelsea Pub. Co., New York 1953.
4. Huang N.E., Shen Z., Long S.R., Wu M.L.C., Shih H.H., Zheng Q.N., Yen N.C., Tung C.C., Liu H.H. The empirical mode decomposition and the Hilbert spectrum for nonlinear and non-stationary time series analysis, Proceedings of Royal Society London A454 (1998) 903-993.

5. Insperger T., Gradisek J., Kalveram M., Stepan G., Winert K., Govekar E., Machine tool chatter and surface location error in milling processes, Journal of Manufacturing Science and Engineering 128, 913-920 (2006).

6. Lajmert P. An application of Hilbert-Huang transform and principal component analysis for diagnostics of cylindrical plunge grinding process, Journal of Machine Engineering 10 (2010) 39-49.

7. Litak G., Kecik K., Rusinek R. Cutting force response in milling of Inconel: Analysis by wavelet and Hilbert-Huang transforms. Latin American Journal of Solids and Structures 10, (2013) 133-140.

8. Litak G., Rusinek R. Dynamics of a stainless steel turning process by statistical and recurrence analyses. Meccanica 47 (2012) 1517-1526.

9. Litak G., Syta A., Rusinek R. Dynamical changes during composite milling: recurrence and multiscale entropy analysis. International Journal of Advanced Manufacturing Technology 56 (2011) 445-453.

10. Litak G., Rusinek R. Vibrations in stainless steel turning: multifractal and wavelet approaches. Journal of Vibroengineering 13 (2011) 102-108.

11. Mann B.P., Insperger T., Bayly P.V., Stepan G., Stability of up-milling and down-milling, part 2: experimental verification, Int. J. Mach. Tools Manuf. 43, 35-40 (2003).

12. Mann B.P., Bayly P.V., Davies M.A., Halley J.E., Limit cycles, bifurcations, and accuracy of the milling process, J. Sound Vibr. 277, 31-48 (2004).

13. Płaska S., Wolszczak P. Zastosowanie analizy MES i pomiarów drgań w procesie ulepszania konstrukcji frezów. In: Innovative Manufacturing Technology. V. 2, Kraków: Instytut Zaawansowanych Technologii Wytwarzania, 2012, 55-62.

14. Sen A.K., Litak G., Syta A., Rusinek R. Intermittency and multiscale dynamics in milling of fiber reinforced composites. Meccanica 48 (2013) 783-789.

15. Tuysuz O., Altintas Y, Feng H-Y. Prediction of cutting forces in three and five-axis ball-end milling with tool indentation effect. International Journal of Machine Tools \& Manufacture 66 (2013) 66-81.

16. Wolszczak P., Płaska S., Dziuba M. Optymalizacja skrawania materiału Inconel 713 podczas procesu wyważania wirników turbosprężarek. Mechanik 6 (2012) 311-318.

17. Wolszczak P., Płaska S., Dziuba M. Wpływ zmiany geometrii narzędzi typu high feed, przeznaczonych do frezowania materiałów trudnoobrabialnych, na ich trwałość. Mechanik 6 (2012) 319-326. 